before modifying the present system, the facts revealed by this inquiry into the emigration of scientists attest the urgency of the situation and seem to point to one or two temporary expedients. What is essential is that the Minister for Science should make sure that, when the results of the present inquiries are at last available, decision and action should not be further delayed because it is found that further facts are required. Creative thinking should clear the way for swift action, including that of educating the public as to what is involved, in which the United States has in the past year or two made such striking and even revolutionary advances.

Moreover, the United States gives generous financial support to scientists and scientific institutions which not only stimulates, but sometimes also initiates, scientific advances and discovery not only in Great Britain but also in many other countries, both advanced and emerging. This is evidenced in practically every issue of Nature.

In other words, while recognizing that the recent Royal Society report should stimulate Britain to put her own seientific house in order (with an essential change of heart at the Treasury), it must be acknowledged that the United States is not only taking, in the form of scientific personnel. but also is generously giving, through her Foundations. Government departments, etc., and thus encouraging and supporting the advancement of science far beyond her own frontiers. This surely reveals the right attitude towards science as an international discipline which ignores national boundaries and differences in race, colour or creed.

\section{MACHINES FOR HIGH-ENERGY NUCLEAR PHYSICS}

\section{Particle Accelerators}

By Prof. M. Stanley Livirıgston and Dr. John P. Blewett. (International Series in Pure and Applied Physics.) Pp. xvi+666. (Now York : MeGraw-Hill Book Company, Inc.; London : McGraw-Hill Publishing Company, Ltd., 1962.) 135s. $6 d$.

THIS book is a welcome addition to the literature of particle accelerators. There are many excellent review articles on the subject varying from semi-popular expositions to highly technical treatises. Until recently, however, comprehensive books on particle aceelerators have been almost non-existent. Yet the audience for such a book is wide, including as it does the accelerator physicist, the engineer, the nuclear physicist and to some extent the non-specialist.

In this respect the authors of Particle Accelerators have succeeded in producing a reasonable balance of all those aspects. Above all, they manage to convey something of the excitement and wonder which still adheres to accelerator building. To quote from their introduction: "The thrill of discovery is the reward of exploration", and again, "The pleasure and excitement of the working crew when a new accelerator is first tuned in to set a now voltage record is something to be remembered for a life-time". Comments like those and ancedotes, now part of the historical development of accelerators, give the book a warmth rarely found in treatises on technology.

Production of high-energy beams of charged particles in the laboratory began in the early 1930's with the Cockcroft and Walton d.-c. generator, the Lawrence cyclotron and the Van de Graaff electrostatic generator. Their impact on nuclear physics was tremendous and by 1940 these machines were commonplace in university laboratories. After the Second World War, the discovery of the principle of phase stability, a better understanding of dynamical principles, coupled with war-time advances in microwaves and electrical engineering, initiated a nex family of large accelerators. These were the frequency modulated eyclotrons, the electron and proton synchrotrons and the betatron. There is no need to elaborate the significant contributions these accelerators have made in elementary particle physics during the past fifteen year's. The largest of those accelerators are the Bevatron at Berkeley, and the $10-\mathrm{GeV}$ machine at Dubna, near Moscow. Later this year similar machines will come into operation at the Rutherford Laboratory in Britain and at the Argonne Laboratory in the United States. This type of accelerator is now referred to as a constant gradient machine.

The success of these machines stimulated designers to seek new methods for increasing both the energy and intensity of existing accelerators. This search was rewarded by the discovery in 1953 of the principle of alternating focusing by Courant, Livingston and Snyder, and at an earlier date by Christophilos. Within the past fow years three proton synchrotrons of this design have come into operation-a European machine at CERN, Geneva, of $25 \mathrm{GeV}$, an American machine at Brookhaven of $28 \mathrm{GeV}$ and a Russian machine in Moscow of $7 \mathrm{GeV}$. The Russians are also building a 70-GeV machine which should come into operation in 1964. In addition, an electron machine of $5 \mathrm{GeV}$, directed by Livingston, has come into operation within the past few months. A similar machine should come into operation in Hamburg later this year.

This brief account of accelerator installations is only indicative of present-day activity in this field and does not include the very large number of smaller machines. Even so, the search for new techniques still goes on. This has led to a new family, still in the design stage, now referred to as fixed-field alternating gradient accelerators. Design studies in extending the range of the present. alternating gradient machines also suggest that these could be extended to $1,000 \mathrm{GeV}$ with a diameter of several miles. The pressure to build such a machine is likely to grow rapidly in the near future.

This 'story' of accelerator development is very well told in the present book. Both authors have participated in the advances of this field and have an intimate knowledge of many of these machines. Livingston, for example, was associated with Lawrence in the early 1930's in cyclotron development. After the War he helped to design the Cosmotron and the AGS at Brookhaven, and recently has directed the electron synchrotron project at Cambridge, United States. Blewett has also been associated with the construction of both the Cosmotron and the $A G S$. In particular, ho has been responsible for the proton linear accelerator injector and for directing recent design investigations in a large international accelerator project.

In their book, separate chapters are devoted to each type of accelerator mentioned here. There are also special chapters on ion sources, particle dynamics, the principle of phase stability, magnet design and shielding. A strong sense of historical development accompanies the description of each machine, which makes enjoyable and stimulating reading. The amount of detailed information recorded by the authors is quite remarkable. In a subject which has always demanded a happy alliance between physicist and engineer the authors have succeeded in giving due weight to each. To the specialist in one or other of these fields the style may at times be too racy, and certain aspects may be treated rather superficially for the book to be a satisfactory formal text-book, but what it lacks in this respect it gains in information and enthusiasm. It is a book that everyone associated with accelerators, as designers, as builders or as users, will profit from and enjoy reading.
W. WAIKINSHAW 